\title{
Attitudes to the Administrative Management of Service Patients with Epilepsy and Related Disorders among Army Physicians
}

\author{
Major R Whiteoak \\ MB, MRCP (UK), RAMC \\ Senior Specialist in Medicine
}

Maj L J Findley

$\mathrm{MB}, \mathrm{MRCP}(\mathrm{UK})$, DCH, RAMC(V)

Visiting Consultant Neurologist

Queen Elizabeth Military Hospital, Woolwich

SUMMARY: The case histories of ten patients suffering from epilepsy or related disorders were sent to all serving Consultant Physicians and Senior Specialists in Medicine in the Army. They were asked their opinions on the PULHEEMS Grading and restriction of duty in each case. In many cases there was a wide range of opinion on the management. Clearer guidelines concerning the diagnosis and administrative management of patients need to be drawn up to allow Service physicians to be consistent and fair to their patients.

\section{Introduction:}

Over the last few years there has been considerable interest in the literature on the sociological consequences of epilepsy and isolated seizures to the individual. In 1982 the Royal Society of Medicine devoted an entire symposium to the subject of Driving and Epilepsy and other causes of impaired consciousness. Harvey and Hopkins ${ }^{2}$ showed considerable variation in the attitudes of neurologists concerning the fitness of patients to drive and also in their interpretation of the existing regulations. They were surprised and disturbed by the results of their survey.

The object of this survey was to examine the attitudes of Army physicians to the employment categories of servicemen with seizure disorders. The existing regulations are brief. The PULHEEMS Classification System JSP $346^{3}$ states:

Epilepsy. Before a diagnosis of epilepsy is made, a certificate from the man's own doctor and a Specialist's recommendation should be obtained. Proven epilepsy, with a few exceptions, is to be assessed (P8). It is unwise, however, to base the diagnosis on the history of one fit.

The Regulations of the Army Medical Services ${ }^{4}$ state:

Epilepsy and similar conditions. Officers and soldiers who are firmly diagnosed as suffering from epilepsy or a similar condition (e.g. convulsions of uncertain origin) are normally to be invalided. If it is considered, nevertheless, that a patient suffering from such a condition should be retained in the Army a full.Medical Board will be held. The proceedings of the Board are to be forwarded to the Defence Medical Services Directorate (EMR) for advice before confirmation. In such cases the patient will not be informed of the recommendations of the Board until it has been confirmed.
Neither regulation. defines epilepsy nor do they differentiate types or causes of epilepsy.

\section{Method:}

Ten case histories of serving personnel or potential recruits were circulated, with a letter of introduction to all serving Army physicians. At the end of each case history were a number of questions concerning administrative management. Respondents were asked to complete the questions as if they were sitting on a Medical Board. Prior approval for the survey was obtained from the Director of Army Medicine.

\section{Results:}

22 out of 23 physicians returned the survey. The case histories and replies are given below.

\section{Patient 1:}

A seventeen year old potential recruit is sent to outpatients for a specialist opinion following his enlistment medical. Between the ages of four and eleven he was treated for "absence attacks". A diagnosis of petit mal epilepsy was confirmed by EEG.

He has had no further attacks for six years and has been off all treatment for five years. There is no other relevant past history or family history. Physical examination is normal. An EEG shows a generalised abnormality with occasional runs of spike and wave discharges compatible with generalised subcortical epilepsy.

Although he has never had a grand mal convulsion would you accept this man for enlistment?

20 respondents would not accept him for enlistment.

2 respondents expressed reservations but would enlist him.

Comment: This patient was referred from the Army Careers Information Office with a recommendation 
from a civilian neurologist that he was fit to serve. Many respondents commented that there would be a high risk of grand mal seizures under the stress of Service life.

\section{Patient 2:}

An eighteen year old recruit who has just begun his basic training is referred by his RMO for a second opinion on his fitness to serve. Between the ages of three and seven he suffered three generalised convulsions not associated with fever and was started on anticonvulsants which were continued until the age of 10 . He had no further convulsions. On enlistment he was referred to the nearest Service hospital where he saw an RAF consultant. No further relevant history or physical findings were elicited and his resting EEG was normal. $\mathrm{He}$ was accepted in a category of P2 FE with the restriction that he should not be allowed to parachute or become aircrew.

Would you investigate this patient further?

Do you agree with the initial PULHEEMS assessment?

Is he fit to serve?

What changes, if any, would you recommend?

15 respondents would do no further investigations.

7 respondents would perform a fasting, sleep deprived EEG.

10 respondents agreed with the initial assessment.

7 respondents disagreed with the initial assessment.

5 respondents reserved judgement depending on the results of the fasting, sleep deprived EEG.

13 respondents would retain him $\mathrm{P} 2 \mathrm{FE}$ although not all agreed with the initial assessment but were unwilling to change it under the circumstances as it might induce hardship.

2 respondents would grade him $\mathbf{P 7}$ and recommend that he be discharged below retention standard irrespective of any further investigations.

6 respondents would grade him P7 below retention standard if the fasting, sleep deprived EEG were abnormal.

1 respondent would grade him P3 but retain him.

Comment: In contrast with Patient 1 , approximately half of the respondents were unhappy to accept a clinical diagnosis of epilepsy on the history in view of the course of events and a normal EEG. Equally, half the respondents felt that this patient should not have been accepted at all, although not all of these were prepared to recommend a change at this stage.

\section{Patient 3:}

A nineteen year old Sandhurst cadet is referred to outpatients. During a series of training exercises some weeks earlier in a spell of hot weather he had collapsed from exhaustion and was observed to have a tonic-clonic convulsion during which he bit his tongue. He was admitted to a local civilian hospital where he was noted to have a rectal temperature of $40.5^{\circ} \mathrm{C}$. A diagnosis of heat stroke was made. After tepid spraying and rehydration with intravenous fluids he made a rapid recovery and physical examination was entirely normal. $\stackrel{2}{\gtrless}$ There were no other features in his history. He was discharged after 48 hours.

An EEG was performed from outpatients. This was $\varrho$ normal as was a subsequent fasting, sleep deprived EEG.

Would you investigate this patient further?

Assuming any further investigations to be normal, $\overrightarrow{0}$ what $\mathrm{P}$ grading would you give this patient and what employment restrictions, if any?

22 respondents unanimously agreed that no further investigations were indicated.

16 respondents would maintain him $\mathrm{P} 2 \mathrm{FE}$.

1 respondent would downgrade him P3R LE if there was $\vec{\circ}$ evidence that the heat stress was trivial.

2 respondents would downgrade him P3R LE for three and twelve months irrespective of the circumstances.

1 respondent would downgrade him P6R BT for an unspecified time.

2 respondents would downgrade him P7R HO for three $\vec{N}$ and six months respectively.

Comment: All respondents were agreed about the diagnosis. The downgradings were purely to protect the patient from further risk of heat injury for the nef $\frac{}{5}$ future and not because any underlying epileptic disordep was suspected.

\section{Patient 4:}

A twenty six year old junior NCO is referred following $\overrightarrow{0}$ a single grand mal convulsion with reliable eye witnes o reports. The attack occurred mid-morning after a good. breakfast although the patient had been up late the nigit before and drunk about eight pints of beer. He did not normally drink to excess. His past medical history was unremarkable but his brother suffers from idiopathic $\stackrel{\circ}{\Phi}$ epilepsy and is on treatment.

Physical examination was normal but a resting EEG was abnormal and compatible with generalised subcortical epilepsy.

The patient is extremely keen to continue to serve. What advice would you give him and what PULHEEMS grading and PES would you give him?

Would you be prepared to change this grading at any time in the future depending on events?

3 respondents would retain him $\mathrm{P} 2 \mathrm{FE}$.

2 respondents would downgrade him P3R LE for 12 months.

13 respondents would downgrade him P7R HO for a range of 12 to 36 months, with the majority 12 months. 4 respondents would recommend invaliding P8 from the Service.

All respondents who did not initially recommend invaliding recognised the need for downgrading if further fits occurred.

Comment: There is a wide range of opinion in this case $N$ which reflects the uncertainty of management of an isolated seizure. 


\section{Patient 5:}

A thirty two year old infantry Colour Sergeant, 2 IC of the mortar platoon, had a grand mal convulsion one evening in the Sergeants' Mess. He had been living in the Mess (married unaccompanied) and drinking very heavily, otherwise there was no relevant history.

On examination he had the features of chronic alcohol abuse but no focal neurological signs. After a few days of alcohol withdrawal symptoms he became entirely normal. Subsequent resting and fasting, sleep deprived EEGs were normal.

$\mathrm{He}$ was referred for alcohol re-education and responded well to the course and was discharged S7R. One year later he has remained well and off alcohol and the psychiatrists are happy to regrade him S2.

Would you be happy for him to resume full, normal duties?

If not, what restrictions would you put on his activities and for how long?

21 respondents would regrade him $\mathrm{P} 2 \mathrm{FE}$.

1 respondent recommended a further year in a category of $\mathrm{P} 3$ or $\mathrm{S} 3$.

Comment: This is a more straightforward case of a single fit complicating chronic alcohol abuse without evidence of an underlying epileptic tendency. Notwithstanding the potential risks of this man's occupation, the majority of respondents were happy for him to resume full duties assuming he remains abstinent from alcohol. Several respondents commented on the need to monitor this, however.

\section{Patient 6:}

A twenty two year old bandsman presents with a history of three episodes of loss of consciousness in four years. The last episode was witnessed as a grand mal convulsion. Physical examination is normal but his EEG confirms a generalised epileptic tendency and he is commenced on treatment with Phenytoin.

$\mathrm{He}$ is keen to continue to serve and his unit are keen to keep him in the band in a downgraded capacity. The patient is aware that promotion is unlikely.

Would you allow him to continue to serve and, if so, in what grading?

1 respondent would make him $P 3$ LE.

13 respondents would downgrade him $\mathrm{P} 7 \mathrm{HO}$. Of these, 4 preferred medical discharge but would be prepared to retain him. 4 out of the 13 would be prepared to upgrade him P3 (Permanent) LE if he was well controlled on treatment.

8 respondents would invalid him (P8) immediately.

Comment: Clearly some physicians were prepared not to follow the advice of the regulations in a straightforward clinical situation where the patient was well motivated to remain in the Army in a suitable occupation, but some commented on the need for medical discharge if the fits were not well controlled. Conversely, some physicians stressed that a medical discharge was mandatory even for a bandsman because of his operational role.

\section{Patient 7:}

A thirty three year old Staff Sergeant was admitted on casevac from Northern Ireland where he was on an accompanied tour. One evening about a week before he had had an episode of disturbed consciousness where he was observed by his wife to be staring ahead unaware of his surroundings. His wife reported that he remained in this state for about twenty minutes and then collapsed with a tonic clonic convulsion. He was transferred to hospital where he was admitted conscious but unresponding with intermittent lashing out of his limbs. After intravenous Diazepam he became normal and examination was then normal. There was no comment on any abnormal signs during his stupor.

In the past he had had a blackout in Cyprus related to alcohol excess but no details available. Since then he had also had a head injury eight years ago rendering him unconscious for 20 minutes. There was no family history but his sister had recently had a cerebro-vascular accident.

He was entered into the First Fit Study of the Royal College of Physicians and by virtue of this was investigated by a full haematological and biochemical screen, resting EEG, fasting and sleep deprived EEG and CT Scan. These were all normal. No drugs were prescribed.

What $\mathrm{P}$ grading and PES with restrictions would you give him?

Would you allow him to return to Northern Ireland where he works in a Headquarters?

4 respondents would retain him $\mathrm{P} 2 \mathrm{FE}$ ?

5 respondents would downgrade him P3R LE although 1 of these recommended he should not return to Northern Ireland.

Comment: In this case the clinical situation suggests a complex partial seizure but the investigations are normal. In contrast to Patient 4 , the situation is much less clear cut and hence no physician recommended a medical discharge at this stage. Several respondents commented on the need to monitor the CT Scan.

\section{Patient 8:}

A thirty one year old Infantry Sergeant presents with an eight month history of headaches associated with numbness and weakness of the left arm lasting about three hours. The attacks occurred at approximately weekly intervals. On one occasion the attack was associated with stiffness in the left arm and intermittent loss of consciousness. He was admitted to hospital where he was noted to be aphasic and have mild left arm weakness. Within a few hours he had made a complete recovery. He was fully investigated in a civilian hospital by CT Scan, EEG, visual evoked responses, lumbar puncture, and bilateral carotid and vertebral angiography which were normal. His EEG showed a diffuse abnormality with left sided emphasis but no focal 
or paroxysmal changes. The other investigations were normal. A diagnosis of migraine was made and he was started on clonidine.

He was referred to a Service hospital for further management. Since commencing clonidine he had had minor headaches but no further neurological disturbance or loss of consciousness. There were no abnormal signs.

7 respondents would downgrade him $\mathrm{P} 3$ LE. Of these 3 would be prepared to upgrade him P2 FE in the future and 4 did not specify.

15 respondents would downgrade him $P 7$ for 12 months. 4 would then upgrade him P3 LE and 4 would upgrade him P2 FE. 7 did not specify the duration of downgrading.

Comment: Non-specific EEG abnormalities are common in migraine although focal neurological deficits and loss of consciousness are not. In this case all respondents clearly regarded his attacks of loss of consciousness as symptomatic of his migraine. Several were prepared to allow no restriction in his activities in the future if his migraine remained controlled off treatment.

\section{Patient 9:}

A twenty seven year old Corporal is referred for assessment. Two years previously he had been involved in a severe road traffic accident where he had been knocked unconscious for several hours but had not fractured his skull. He appeared to make a complete recovery but then developed fairly frequent episodes of an abnormal smell and deja vu feelings lasting a few minutes. These episodes occurred once or twice per month. An EEG confirmed a left temporal lobe focal abnormality and a CT Scan suggested "scarring" in this region. He was started on Epilim and his attacks were abolished. He had never at any stage had an attack where he lost consciousness.

How would you grade him now and in the future assuming he has no further attacks on treatment? 1 respondent would keep him P2 FE.

7 respondents would downgrade him P3 LE (permanent).

12 respondents would downgrade him $\mathrm{P} 7 \mathrm{H} 0$. Of these 4 would make this a permanent grading while 8 would consider upgrading him. 2 respondents would be prepared to try him off treatment in the future and regrade him $\mathrm{P} 2 \mathrm{FE}$ if he remained fit free.

2 respondents would medically discharge him P8.

Comment: Some respondents regard simple partial seizures, where consciousness is not impaired, as a less serious problem than generalised seizures but others clearly do not.differentiate types of epilepsy. Those respondents who favoured a permanent downgrading would be prepared to offer the patient a medical discharge if he was unhappy to continue to serve in a downgraded capacity.

\section{Patient 10:}

A forty two year old Quartermaster Captain presents with an unwitnessed blackout during which he was 3 incontinent. Past history and examination are normal but subsequent investigation shows him to have a frontal $\bigcirc$ meningioma. This was resected and he was put ono phenytoin and graded P7 R HO Ex N.I. After one year? he had no further fits and there was no sign of recurrence $\overrightarrow{\bar{F}}$ of his tumour. He was weaned off treatment.

Assuming he has no further fits how would you manage his subsequent gradings and employment standards?

1 respondent would regrade him $\mathrm{P} 2 \mathrm{FE}$.

10 repondents would regrade him P3 LE. Of these 20 would make this a permanent grading, 7 would upgrade $\vec{O}$ him in 12 months and 1 would upgrade him 24 months. 11 respondents would make him P7 $\mathrm{HO}$. Of these $2 \vec{\sigma}$ would make this a permanent grading and the remainder would upgrade him between 6 and 24 months later.

Comment: This patient can be regarded as having been? cured of the underlying cause of his seizure but a smallw. risk of further seizures must remain particularly following the cessation of treatment.

\section{Discussion}

In several of the above patients there is considerabtevariation in the administrative management Бy? physicians, which is a matter of concern if we are to consistent and fair. Certain problem areas can defined. Firstly, the poor assessment of the risk $\frac{O}{8 R}$ epilepsy in the potential recruit is commonfy $\vec{\bullet}$ encountered. It is interesting to note that tees combination of a past history of petit mal epilepsy w an abnormal EEG was considered by most physicians a high risk for adult epilepsy, whereas a documented history of three major seizures in childhood with no further attacks or treatment and a normal EEG was regarded more favourably by half the respondents. Under the current regulations the rejection of both these $\overrightarrow{\vec{O}}$ cases is recommended and probably justified. By 3 contrast in the United States Army ${ }^{5}$, epileptics are considered for enlistment if they have had no seizures: since the age of five or they have been free from attacks $\exists$ on no treatment for the preceding five years. In such patients a recent EEG is always submitted for evaluation.

A second area of concern is the isolated seizure. $\mathrm{By} \stackrel{\mathrm{N}}{\rightleftharpoons}$ definition such patients do not have epilepsy and it has? been traditional teaching that they are not investigated 3 unless there are clinical clues which suggest a structurali brain lesion. Studies of groups of patients following first seizures, however, suggest a significant proportion develop epilepsy. Johnson, de Bolt and Long ${ }^{6}$ followed up 77 young U.S. Naval personnel aged between 18 and 30 for about four years. $64 \%$ had one or more further seizures. Cleland et $\mathrm{al}^{7}$ reported that $39 \%$ of 70 patients developed epilepsy within a mean follow-up time of fourn years nine months. $90 \%$ of these occurred within twoN 
years. Under the auspices of the Royal College of Physicians a major prospective study of first seizures which aims to assess the recurrence rate over a five year period is being carried out. The study will also evaluate various epidemiological risk factors, the value of investigations in predicting recurrence and the causes of seizures including the role of life events in precipitating seizures. The results of this study will clearly affect our future management. Patients 3, 4, 5, 7 and 10 all illustrate isolated seizures under a variety of circumstances. The range of views, particularly in patient 4 , reflects the uncertainty in clinical practice as a whole. The current regulations provide no assistance.

In civilian life, following a single seizure, the Department of Transport suggest a period of ineligibility from driving for six to twelve months and this is usually extended to two years if there is evidence (clinical, EEG or otherwise) of a primary cerebral cause. There is no foundation for this in law as the current Driving Licence Regulations (1981) make no mention of the eligibility to hold a driving licence after a single seizure. Nevertheless, it behoves us in the military to be at least as conservative in our approach as in civil practice, bearing in mind the added potential risks in Service life. If we consider Case 5, Army physicians were in agreement that this patient could return to full duties including handling mortars, yet, by law this patient would be debarred for life from driving heavy goods vehicles. Perhaps the law is too severe in this case as many neurologists would regard such a fit as nonepileptic. However, if like the Army Regulations, the law does not define epilepsy the suggestions of Harvey and Hopkins ${ }^{2}$ for defining and diagnosing epilepsy would be a useful addition to the Army Regulations:

\section{A. Definitions:}

i) A seizure is an abnormal, paroxysmal discharge of cerebral neurones clinically apparent either to the subject or to an observer. Unless there are clear precipitating factors of exceptional occurrence, all seizures, of whatever type, are presumed to be epileptic. Exceptions include:

(a) A seizure resulting from cerebral anoxia (during syncope or during profound hypotension).

(b) Insulin-induced hypoglycaemia.

(c) Seizures occurring as an unwarranted effect of drugs.

(d) Seizures occurring only in association with fever, before the age of four years, and unaccompanied by neurological signs. Such seizures are called "febrile convulsions".

(e) Such other exceptions as may be defined from time to time.

ii) Epilepsy is the occurrence of more than one nonfebrile epileptic seizure of any type.

\section{B. Diagnosis:}

The diagnosis of epileptic seizure and epilepsy can be made by any registered medical practitioner, though the opinion of a Consultant Neurologist may be helpful. Investigations such as electroencephalography are not a prerequisite for the diagnosis.

We would substitute Specialist Physician for Consultant Neurologist in the recommendation for diagnosis.

The third area of concern is the management of cases with an established diagnosis of epilepsy. The Regulations are quite clear on this, yet many epileptics continue to serve in a downgraded capacity restricted from driving, handling weapons and live ammunition. In the Royal Navy, patients with epilepsy are submitted to a Board of Survey (equivalent to a Medical Board) followed by a Royal Naval Manpower Employment Board. Both Boards are chaired by the same person, a medical officer. Patients are not automatically medically discharged. In the Royal Air Force, the general rule is that epileptics are grounded but not discharged solely because of epilepsy. In the United States Army ${ }^{5}$ epilepsy of all types is considered grounds for medical discharge only if seizures are not adequately controlled by standard drugs which are relatively non-toxic and which do not require frequent clinical and laboratory reevaluation. Epileptics who are retained are barred from flying and the combat arms. In the British Army we recommend that the policy of ratification of Boards by the Ministry of Defence for known epileptics is strictly adhered to where retention in the Service is being considered.

The fourth area of concern is the management of patients with minor seizures without loss of consciousness. In civil life the Driving Regulations do not differentiate types of epilepsy when considering ineligibility to drive. This is probably reasonable as many cases of minor epilepsy including transient disturbances of consciousness of which the patient is unaware, and can lead ultimately to a major seizure. Although the social implications of minor seizures are much less severe than generalised seizures, the risk of minor seizures evolving to secondary generalised seizures means that there is no justification for managing minor seizures any differently from the administrative point of view.

In conclusion, the management of every case must be judged on its individual merits. The clinical situation, age, seniority, length of service, occupation and place of duty are all relevant factors to consider. It is hoped that this survey has helped to focus attention on a difficult problem and clarify thoughts on management. The survey in itself was an interesting exercise which may have application in other clinical problem areas.

\section{REFERENCES:}

1 The Royal Society of Medicine. International Congress and Symposium Series Number 60. Driving and Epilepsy and other causes of impaired consciousness. 1983.

2 HARVEY $P$ and Hopkins $A$. Views of British Neurologists on Epilepsy, Driving and the Law. Lancet $1983 ; \mathbf{i}: 401-404$. 
3 Joint Services Procedures 346. PULHEEMS A Joint Services System of Medical Classification. 1976; Serial 0430: 4-9.

4 Regulations for the Army Medical Services. Revised, 1974; Serial 04164: 4-28.

5 United States Army Regulations 40-501. Standards of Medical Fitness. 2-31.
PUBLICATIONS: ABSTRACTS AND SUMMARIES, 1985

MAJOR T O JEFFERSON, RAMC and V M TAYLOR

JeFFERSON T $O$ and TAYLOR V M. Perinatal Mortality in Infants of Two Different Ethnic Groups. Family Practice 1985; 2: 175-176.

Abstract: In a retrospective survey of 1433 Chinese and 1130 Gurkha (Nepali) births in an Armed Services environment in Hong Kong, neonatal mortality rates were analysed according to birthweight.

The data thus obtained were compared with similar data from published surveys with the aim of ascertaining any differences in mortality rates.

\section{MAJOR A HENDERSON, RAMC and A S LAWSON}

Henderson A and LAwSON A S. Frequency distribution and $95 \%$ range of a variety of commonly measured blood constituents in healthy Nepalese donors. J Trop Med Hyg 1985; 88: 21-24.

Summary: The most frequently measured biochemical and haematological blood constituents were assayed in 431 healthy Nepalese blood donors. As only 19 subjects were female, analysis of their data was confined to calculation of the geometric mean. For the 412 males frequency distribution, geometric mean and $95 \%$ range were calculated for each constituent. Male and female male values were compared. It is hoped that $95 \%$ normal ranges might provide a better standard against which to compare data from Nepalese patients than the previously used reference ranges derived from ethnically different populations.
6 Johnson L C., de Bolt W L and Long M T Diagnostic factors in adult males following initial seizures. Arch Neurol 1972; 27: 193-197.

7 Cleland P G et al. Prognosis of seizures in adult life. BrMedJ. 1981;283: 1364.

\section{CAPT T O JEFFERSON and MAJOR P A RASER}

JEFFERSON $T$ O AND RASER $P$ A. Non-Simulated Casualty Workload in 2 Field Hospital during Exercise "Bold Gannett". Giornale Di Medicina Militare 198 3: 265-268.

Summary: Throughout Exercise Bold Gannett, non simulated patients requiring operative or intensive care were forwarded to a local civilian hospital after processing at the Field Hospital. The results of a survey of first attendances are reported and analysed. 